\title{
PORQUE INTEGRAR ENSINO E SERVIÇO DE ENFERMAGEM NOS HOSPITAIS UNIVERSITÁRIOS
}

\author{
Maria Ivete Ribeiro de Oliveira*
}

$\mathrm{RBEn} / 03$

OLIVEIRA, M. I. R. - Porque integrar Ensino e Serviço de Enfermagem nos hospitais Universitários. Rev. Bras. Enf.; Rio de Janeiro, 28: 37-41, 1975.

1. Há precisamente seis anos, a Escola de Enfermagem da Universidade Federal da Bahia, juntamente com a Organização Panamericana da Saúde promoveu nesta cidade do Salvador, um Seminário sobre "Integração de Ensino e Serviço de Enfermagem em Hospitais Universitários".

Reuniram-se, naquela ocasião, diretoras e professoras de escolas de enfermagem com o objetivo de estudar sistemas técnico-administrativos que permitissem o desenvolvimento de métodos necessários à integração do ensino e serviço, visando de um lado, a melhoria do padrão de assistência ao paciente e seus familiares e, de outro, fortalecer a aprendizagem dos alunos através de u.m ensino realista, renovado pela pesquisa de campo. Os frutos desse encontro estão sem dúvida, a merecer uma avaliação, tal a relevância da matéria discutida.

2. Ontem como hoje reconhece-se que muito mais precisa ser feito para evitar essa prejudicial dicotomia - educação e serviço. Perseguindo quase sempre, objetivos diferentes 0 ensino se faz, muitas vezes, divorciado da realidade, sem utilização plena das oportunidades que lhes oferecem os campos de prática e sem maior influência na renovação da prática profissional; doutra parte, sem incorporar novos métodos de trabalho, sem maior contato com as diretrizes educacionais e cada vez mais pressionado pelo volume de tarefas inadiáveis, o serviço tende a esclerosar-se na repetição estéril de rotinas ultrapassadas.

Tal estado de coisas continua suscitando reação, principalmente, agora em que se instalam novos hospitais-escola e se ampliam os campos de prática hospitalar para os estudantes de enfermagem, através da utilização da rede hospitalar governamental.

3. Entre as professoras das escolas de enfermagem, à medida em que aumenta a consciência de suas múltiplas responsabilidades nas áreas de ensino, pesquisa

* Professora da Escola de Enfermagem da Bahia. 
OLIVEIRA, M. I. R. - Porque integrar Ensino e Serviço de Enfermagem nos hospitais Universitários. Rev. Bras. Enf.; Rio de Janeiro, 28: 37-41, 1975.

e serviço, cresce o interesse de todas para uma melhor definição dos papéis a desempenharem nos chamados "laboratórios de prática". Mais voltados, até então para as atividades de ensino, nem sempre aliás definido de modo claro, a contribuição das professoras nas outras áreas é ainda inexpressiva. Na realidade, excetuando-se alguns exemplos aqui e ali, as professoras-enfermeiras têm evitado assumir responsabilidades para uma assistência continuada aos pacientes nos hospitais utilizados para campo de prática das estudantes. Tal procedimento resulta; inevitavelmente, na perda de autoridade para exercerem controle sobre a qualidade de assistência de enfermagem prestada e influenciar no estabelecimento de modelos de prática profissional que possam servir de padrão para as estudantes ou colegas e, finalmente, para criação de um ambiente que permita uma aprendizagem mais dinâmica.

As instrutoras de escolas de enfermagem, dizia Clarice Ferrarini referindo-se à necessidade de melhor formação para as enfermeiras, "deveriam ter maior vivência no campo hospitalar. Sem estarem integradas nas equipes de trabalho, ficam alheias aos problemas gerais da enfermaria, inseguras e sem iniciativa para planejarem as atividades do estudante".

Recebidas como visitantes na maioria das situações e, portanto, tolhidas para o livre desempendo profissional, restam as alternativas de executarem tarefas de acordo com as especificações da unidace ou do hospital ou transferirem às enfermeiras do campo os encargos de supervisão das estudantes em estágios.

Em qualquer das hipóteses, porém, as professoras vão se distanciando cada vez mais da prática profissional e, com isto, ampliando a distância entre a teoria e a prática, aprofundando a dissociação entre educação e serviço, trazen- do como conseqüência uma deformação profissional.

Numerosos tem sido os motivos apontados para esse estado de coisas, devendo-se ressaltar os decorrentes da origem histórica do ensino da enfermagem e das estruturas administrativas dos hospitais-escola.

4. Tentando evitar incorrer nos mesmos erros que, por longos anos, prejudicara o pleno desenvolvimento da enfermagem norte-americana, cuja formação estivera subordinada aos interesses do serviço das instituições hospitalares, as educadoras brasileiras foram aconselhadas a estabelecerem, de início, uma distinção entre educação e prestação de serviço. A medida visava zelar pela qualidade do ensino e proteger docentes e alunos da inevitável utilização destes para cobrirem as necessidades dos vários horários de trabalho hospitalar. As conseqüências do divórcio, ainda hoje prevalentes, não se fizeram esperar; as enfermeiras, sempre mais absorvidas com os aspectos administrativos e, cada vez menos dedicadas ao cuidado ao doente, não vêem como podem colaborar no ensino. Suas energias são consumidas pelos problemas resultantes da pressão do trabalho, em circunstâncias muitas vezes adversas - salário pouco compensador, sistema de trabalho em rodízio nos vários turnos, pessoal auxiliar em quantidade e qualidade deficiente etc. As professoras-enfermeiras, de outra parte, preocupadas com o desempenho de suas tarefas docentes, procuram excluirem-se da demanda do serviço restringindo-se, não raro, ao ensino de sala de aula. As tentativas até agora feitas para reaproximá-las num trabalho de mútua colaboração não tem trazido os efeitos desejados.

Grandes esforços estão sendo feitos em algumas escolas de enfermagem vi- 
OLIVEIRA, M. I. R. - Porque integrar Ensino e Serviço de Enfermagem nos hospitais Universitários. Rev. Bras. Enf.; Rio de Janeiro, 28: 37-41, 1975.

sando buscar uma solução satisfatória. A Escola de Enfermagem da Universidade Federal da Bahia vem tentando estabelecer um modelo de trabalho conjugado - ensino e serviço - que tem permitido uma participação mais ativa das professoras nas atividades assistenciais e administrativas. A estrutura organizacional garante às professoras assumirem os cargos de chefia de enfermagem no hospital universitário, com responsabilidade para definirem as ciiretrizes do trabalho técnico-administrativo. A experiência, seguramente inédita no país, carece ainda de uma avaliação mais detalhada de seus resultados.

A Escola de Enfermagem de Ribeirão Preto vem buscando também essa integração tendo inclusive feito alguma avaliação. Ferreira Santos por exemplo, identificou que as instrutoras esperam, que "as enfermeiras sejam educadoras e administradoras". "A descontinuidade porém, nos propósitos de esclarecerem as situações e definirem os papéis, continua sendo fonte de muita indeterminação e de conflito".

As enfermeiras, por outro lado, mostraram-se insatisfeitas em relação às suas colegas, porque "as tarefas deixam de ser feitas", "pelas críticas recebidas, à sua enfermaria". Ambas, todavia, esperam que haja maior solidariedade entre os membros da própria classe, de modo a não ser necessário escudarem-se sob a proteção médica. Dessa situação conflitava, a solução conjunta dos problemas dos pacientes, ou mesmo dos problemas administrativos dele decorrentes, fica para segundo plano, num desperdício de energias e habilidades.

5. De outra parte, as estruturas administrativas dos hospitais-escola têm dificultado a integração ou a unificação dos dois grupos. Planejado quase sempre, para atender os interesses do ensino e da pesquisa médica, tais institui- ções, reservando para a enfermagem na maioria dos casos a mera posição de "Serviço Técnico-Auxiliar", deixam pouca margem para um trabalho conjugado. São numerosas as linhas hierárquicas a que estão subordinadas, delongando decisões. A presença das docentes de enfermagem no Hospital quando não ignorada ou incompreendida, é aceita se contribui para ajudar o serviço ou colaborar nas pesquisas em andamento; quanto às estưdantes, desde que não exijam maiores atenções e não criem problemas, são recebidas com mais satisfação porque aliviam um pouco a sobrecarga de trabalho do pessoal de enfermagem.

Além desses, outros fatores agravam a dicotomia ensino-serviço, entre os quais podem ser lembrados: o regime de trabalho docente em tempo parcial, impossibilitando a compatibilização das tarefas nas três áreas já mencionadas, especialmente, em virtude da própria natureza da prática profissional. Acresce a tudo isso, também, um certo comodismo para limitação das atividades ao mínimo exigido.

A percepção desses e de numerosos outros problemas não tem faltado. ainda Ferreira Santos quem aponta, em sua tese de doutoramento, a necessidade sentida pelas instrutoras da escola de enfermagem estudada quanto ao:

a) "estabelecimento claro das atribuições da professora da Escola quando está na enfermaria e das atribuições que pertencem à enfermeira;

b) definição da hierarquia entre as duas: são colaboradoras do mesmo nível? Há obrigação de supervisão por parte da instrutura em relação à enfermeira?

c) há reconhecimento de que a professora é autoridade também em relação aos auxiliares de enfermagem e atendentes?" 
OLIVEIRA, M. I. R. - Porque integrar Ensino e Serviço de Enfermagem nos huspitais Universitários. Rev. Bras. Enf.; Rio de Janeiro, 28: 37-41, 1975.

Cremos que a solu.ção dos inúmeros inconvenientes aqui apontados poderão vir, na medida em que as estruturas hospitalares possibilitarem uma interdependência entre as escolas e os departamentos de enfermagem. Aquelas precisam estar, legalmente investidas de autoridade para exercerem controle sobre a qualidade de assistência de enfermagem, para introduzir novas técnicas de trabalho que resultem em maior rendimento e melhor utilização dos parcos recursos humanos disponíveis. Para isto, além de uma definição mais clara quanto aos objetivos do hospital referente à sua contribuição na formação de pessoal de enfermagem seria necessário o apoio da própria estrutura organizacional, assim traduzida:

5.1 - Presença de um representante da Escola de Enfermagem nos Conselhos deliberativos dos hospitais, permitindo não só informar aos seus membros a respeito da programação do ensino e a necessária compatibilização com as demais atividades do hospital, bem como para contribuir na solução de problemas que afetam o bom funcionamento da instituição.

5.2 - Elevação da posição de Enfermagem na estrutura organizacional da categoria de mero serviço auxiliar ao nível de Departamento ou Divisão, de modo a garantir o seu direto acesso à Direção do Hospital.

A necessidade que tem a Enfermagem para relacionar-se diretamente com as diversas áreas do hospital, as decisões que precisam ser tomadas, as responsabilidades decorrentes da prestação ininterrupta dos seus serviços a pacientes internos, nos vários níveis de cuidados, os encargos com a educação permanente de seu pessoal, a atenção a pacientes externos, podem justificar perfeitamente tal pretensão.
5.3 - Estabelecimento de uma hierarquia de enfermagem no hospital, à semelhança daquela existente entre o grupo profissional médico. Tomando como base o critério de competência técnico-profissional, professores, auxiliares de ensino, médicos residentes, internos e estudantes formam, no hospital um grupo único por meio do qual os problemas médicos dos pacientes, sob seus cuidados, podem ser estudados questionados e resolvidos. A distribuição dos encargos de ensino pesquisa e serviço pode ser planejada, tendo em vista as inclinações pessoais e preparo específico e disponibilidade de pessoal. A natural competição profissional que, quase sempre, se estabelece entre os membros do grupo, traz como benefício a descoberta de novos valores, assegurando, assim, um continuado processo de aprendizagem, ampliação do conhecimento e renovação das práticas. A estrutura do poder é naturalmente institucionalizada e a autoridade decorre do grau de responsabilidade assumida.

6. A implantação de sistema semelhante na enfermagem não é tão fácil, sobretudo, pela falta de tradição e do tênue delineamento científico de sua prática; cremos, todavia, ser perfeitamente possível. O rodízio desejável, entre os membros do corpo docente nas três áreas requer melhor preparo e aprendizagem de novos papéis. A demanda exigida pelo atendimento ininterrupto do serviço deve contar com a indispensável participação de diferentes categorias de pessoal, cabendo ao Hospital fazer a provisão necessária. A divisão de trabalho, entre todos deve obedecer o planejamento racional para melhor aproveitamento das habilitações e potencialidades.

Estudos sobre atividades de pessoal de enfermagem, conduzidos até agora, entre nós, comprovam um grande desper- 
OLIVEIRA, M. I. R. - Porque integrar Ensino e Serviço de Enfermagem nos hospitais Universitários. Rev. Bras. Enf.; Rio de Janeiro, 28: 37-41, 1975.

dício de energias, principalmente da enfermeira. O desempenho de tarefas burocráticas (escrituração, controle de material, de roupa, equipamento, etc.), além de outros serviços mais característicos da dietética, farmácia, almoxarifado, limpeza, etc., consomem mais de $50 \%$ do seu tempo, em detrimento de atividades mais específicas e, para as quais recebeu formação. Nem sempre a administração do hospital tem conhecimento desses desvios. A enfermagem, em virtude de ser um dos poucos a oferecer serviços ininterrupto na instituição, vai absorvendo numerosas atribuições pondo em perigo a perda daquelas que lhes compete.
Finalmente, um outro fator que dificulta o tipo de sistema proposto, decorre da falta, ainda predominante, de uma certa caracterização de independência de trabalho profissional. Esta, todavia, somente poderá ser obtida na proporção em que conhecimento, experiência, habilidade e atitude sejam canalizados para a solução de problemas de enfermagem e sistematização de um saber específico.

É necessário pois, estabelecer o entrosamento entre Escolas e Hospitais de modo que se criem condições que permitam um trabalho conjugado de ensino e serviço e diminuição da distância entre conhecimento, aplicação e plena utilização das lideranças e talentos. 